\title{
RANCANG BANGUN TANGKI PEMANAS PADA DESTILATOR BIOETANOL DENGAN SISTEM CONTINUE BERKAPASITAS 5 LITER/JAM UNTUK SEKALA UMKM
}

\author{
Muh Rizqi Maulana \\ Fakultas Teknik, Program Studi Teknik Mesin \\ Universitas Muria Kudus \\ Email: 201454101@std.umk.ac.id \\ Rochmad Winarso \\ Fakultas Teknik, Program Studi Teknik Mesin \\ Universitas Muria Kudus \\ Email: rochmad.winarso@umk.ac.id \\ Rianto Wibowo \\ Fakultas Teknik, Program Studi Teknik Mesin \\ Universitas Muria Kudus \\ Email: rianto.wibowo@umk.ac.id
}

\begin{abstract}
ABSTRAK
Bioetanol adalah cairan yang dihasilkan dari proses fermentasi gula dari sumber karbohidrat dengan bantuan mikroorganisme, Bioetanol merupakan bahan bakar yang dapat digunakan untuk menggantikan bahan bakar fosil. Dimana untuk proses produksi etanol sebagai bahan bakar diperlukan adanya kapasitas yang bisa mencukupi kebutuhan tersebut. Destilator sebagai pengolah bioethanol diperlukan adanya tangki pemanas yang dapat digunakan sebagai proses penguapan dalam skala besar. Metode yang digunakan meliputi studi literatur, proses perancangan, proses manufaktur. Pada hasil penelitian telah dibuat tangki pemanas dengan sistem continue otomatis dan memiliki kapasitas 25 liter dengan dimensi tangki pemanas meliputi tinggi tangki $675 \mathrm{~mm}$ dan diameter $400 \mathrm{~mm}$. Hasil etanol yang didapatkan sebanyak 2,35 liter/jam dengan tingkat kemurnian etanol $91 \%$.
\end{abstract}

Kata kunci: Bioetanol, Distilator, Tangki Pemanas, Kapasitas

\section{ABSTRACT}

Bioethanol is a liquid produced from the fermentation process of sugar from carbohydrate sources with the help of microorganisms, Bioethanol is a fuel that can be used to replace fossil fuels. Where to process the production of ethanol as a fuel there is a need for a capacity that can meet these needs. Destilator as a bioethanol processor requires a heating tank that can be used as a large-scale evaporation process. The method used includes literature study, design process, manufacturing process. The results of the research have made a heating tank with an automatic continue system and has a capacity of 25 liters with the dimensions of the heating tank covering a tank height of $675 \mathrm{~mm}$ and a diameter of $400 \mathrm{~mm}$. The results of ethanol obtained were 2.35 liters / hour with an ethanol purity level of $91 \%$.

Keywords: bioethanol, destilator, heating tank, capacity 


\section{PENDAHULUAN}

Seiring berjalannya waktu sumber daya alam khususnya bahan bakar semakin lama semakin berkurang. Bahan bakar alternatif adalah bahan bakar yang dapat digunakan untuk menggantikan bahan bakar konvensional. Ini menuntut kita untuk dapat menghasilkan bahan bakar selain bahan bakar fosil/minyak bumi karena minyak bumi merupakan sumber daya alam yang tidak dapat diperbaharui. Bahan Bakar Minyak, yang lebih kita kenal dengan BBM merupakan bahan bakar yang diproses dan diolah dari sumber daya alam yang tidak dapat diperbaharui. Karena sifatnya yang tidak dapat diperbaharui ini maka minyak sebagai sumber bahan bakar akan semakin menipis dan habis pada suatu saat nanti. Bahan bakar minyak merupakan sumber energi utama dalam menggerakkan roda kehidupan dunia, termasuk didalamnya roda ekonomi.

Bioetanol adalah etanol yang dibuat dari biomassa yang mengandung komponen pati atau selulosa, seperti singkong dan tetes tebu, dalam dunia industri, etanol umumnya digunakan sebagai bahan baku industri turunan alkohol, campuran untuk minuman keras seperti sake atau gin, serta bahan baku farmasi dan kosmetika [1].

Pada penelitian [2] telah dirancang alat destilaor bioetanol dengan dimensi sebagai tangki pemanas menggunakan material plat Stainless Steel 304 yang berdiameter $400 \mathrm{~mm}$ dengan ketinggian $500 \mathrm{~mm}$.

Pada penelitian berikutnya [3] telah dikembangkan alat destilator bioetanol dengan tingat kemurnian alkohol $76 \%$. Kemudian berlanjut pada penelitian [4] sehingga diperoleh tinngkat kemurnian $92 \%$ pada penelitia tersebut.

Dilaporkan pada penelitiain sebelumnya bahwa proses rancang bangun pada tangki pemanas destilator bioetanol masih perlu adanya penyempurnaan atau perbaikan dari proses pengoprasionalan sistem continue nya. Dimana untuk sistem continue pada tangki pemanas sebelumnya masih dilakukan secara manual, sehingga masih kurang dari segi efisiensinya.

Untuk tangki pemanas pada destilator bioetanol ini akan dilakukan proses penyempurnaan dari sistem control continue nya. Dimana untuk sistem kontrol pada tangki pemanas ini akan disempurnakan dengan penambahan sensor untuk proses kerja continue secara otomatis.

\section{METODOLOGI}

Tahap proses perancangan Rancang Bangun Tangki Pemanas Pada Destilator Bioetanol Dengan Sistem Continue Berkapasitas 5 Liter/Jam Untuk Skala UMKM dapat dilihat pada gambar 2. dibawah ini 


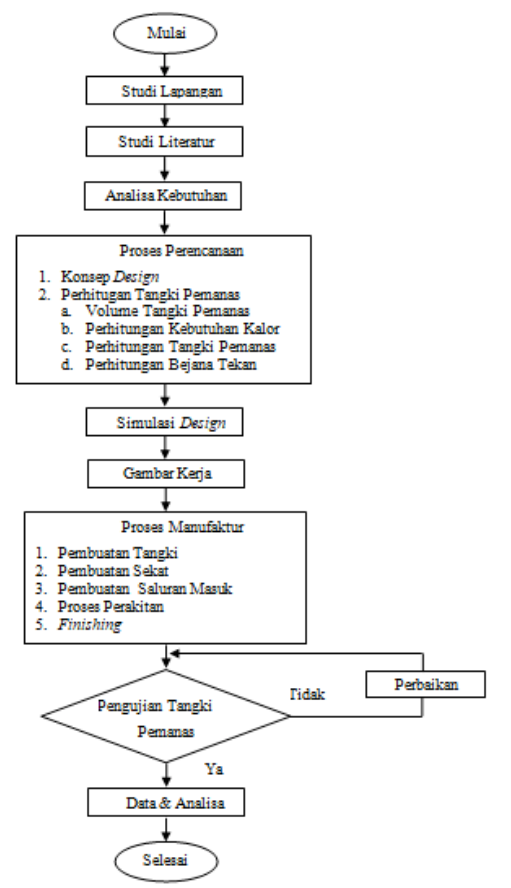

\section{Gambar 1. Diagram alir rancang bangun}

Studi literature merupakan satu cara yang dipakai data untuk menghimpun data-data yang berhubungan dengan tangki pemanas dalam suatu penelitian. Konsep design pada tangki pemanas dapat dilihat dari analisa kebutuhan, dimensi prinsip kerja serta material yang digunakan untuk tangk pemanas. Perhitungan pemanas meliputi volume tangki pemanas, perhitungan kebutuhan kalor, perhitungan tangki pemanas, perhitungan bejana tekan. Simulasi design bertujuan untuk menentukan design untuk menentukan hasil output simulasi adalah von mises stress, displacement, strain dengan tekanan 5 bar pada tangki pemanas. Gambar kerja dipergunakan untuk membirakn informasi mengenai bentuk ukuran, jumlah dan cara membuat suatu benda. Proses manufaktur meliputi pembuatan tangki, pembuatan sekat, pembutana saluran masuk, proses perakitan. Pengujian tangki pemanas bertujuan untuk menentukan aman tidaknya sistem kerja tangki pada temperature tertentu. Untuk gambar tangki pemanas dapat dilihat pada gambar 2 dibawah ini :

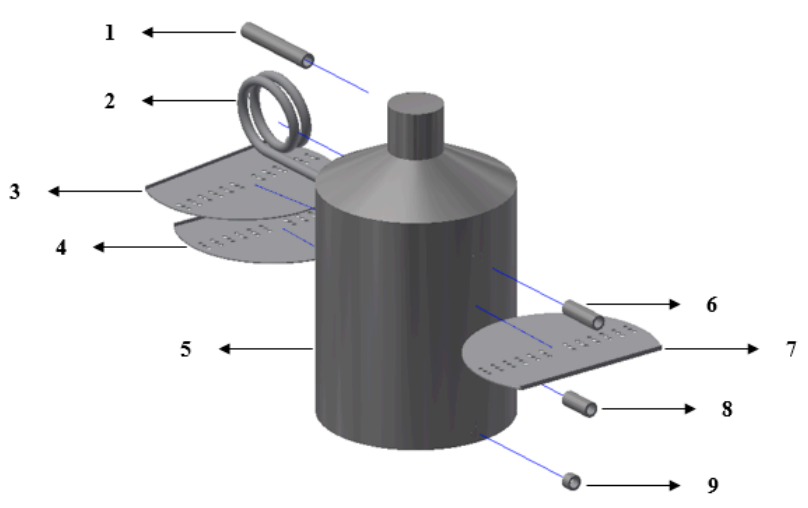

Gambar 2. Tangki pemanas 
Keterangan:

1. Saluran penyambung

2. Saluran sprayer

3. Sekat 1

4. Sekat 2

5. Tangki

6. Saluran masuk

7. Saluran pelimpah

8. Saluran pembuangan

Prinsip kerja dari tangki pemanas destilator bioetanol 5 liter/jam adalah sebagai berikut :

1. Cairan bahan baku yang mengandung $90 \%$ etanol dan $10 \%$ air dimasukkan kedalam bak.

2. Cairan bahan baku dipompa dan disemprotkan ke dalam tangki pemanas melalui saluran sprayer.

3. Semprotan cairan bahan baku fermentasi akan mengisi tangki pemanas.

4. Cairan bahan baku fermentasi akan mengalir melalui sekat - sekat yang ada didalam tangki pemanas.

5. Cairan bahan baku fermentasi pada tangki pemanas akan dipanaskan sehingga akan terjadi proses penguapan.

6. Selanjutnya uap akan mengalir menuju ke menara refluks untuk proses kondensasi dan menuju ke kondensor untuk proses pendinginan sehingga dihasilkan bioetanol.

\section{HASIL DAN PEMBAHASAN}

\subsection{Proses Perencanaan}

Perhitungan tangki pemanas destilator sistem continue dibutuhkan proses pehitungan untuk mempermudah proses pembuatan atau perancangan. Dalam proses perhitungan Tangki Pemanas meliputi perencanaan volume tangki pemanas, peritungan kebutuhan uap ruang tangki pemanas dan penguapan, perhitungan waktu penyulingan, perhitungan kalor total, perhitungan kebutuhan bahan bakar.

Perencanaan spesifikasi Tangki Pemanas Destilator merupakan hal yang penting untuk menentukan seberapa maksimal hasil dari output pada proses kerja destilator tersebut. Untuk dimensi tangki pemanas dapat dilihat pada gambar 3 dibawah ini.

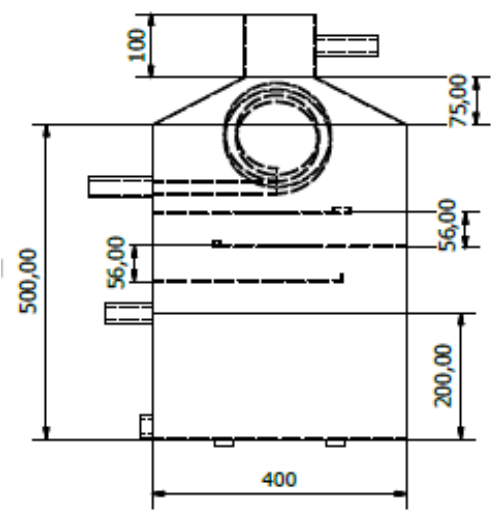

Gambar 3. Dimensi Tangki pemanas 
Perencanaan volume pada tangki pemanas bertujuan untuk menentukan seberapa besar kapasitas bahan yang mampu ditampung pada tangki pemanas itu sendiri.

Volume tangki pemanas dihitung menggunakan persamaan berikut :

$\mathrm{V}$ bahan baku $=\pi \cdot \mathrm{r}^{2} \cdot \mathrm{t}$

Volume tangki total dapat dihitung menggunakan persamaan berikut :

V tangki total $=\pi \cdot r^{2} \cdot t$

Volume ruang penguapan dapat dihitung menggunakan persamaan berikut :

$\mathrm{V}=\mathrm{V}$ tangki $-\mathrm{V}$ bahan baku

Perencanaan kebutuhan uap tangki pemanas dan penguapan pada tangki pemanas bertujuan untuk menentukan kebutuhan uap ruang tangki pemanas itu sendiri.

Kebutuhan uap $=\frac{\text { kapasitas produksi }}{\text { presentase }}$

Proses perhitungan waktu penyulingan pada proses destilasi bertujuan untuk mengetgahui berapa lama waktu penyulingan tersebut.

Waktu penyulingan $=\frac{\text { Volume bahan baku }}{\text { Kebutuhan uap }}$

Panas yang dibutuhkan untuk memanaskan bahan baku fermentasi yang akan didestilasi Menghitung Q air

$\mathrm{Q}$ air (sensible $)=\mathrm{m} \cdot \mathrm{c} \cdot \Delta \mathrm{T}$

Q air $\quad=\mathrm{m} . \Delta \mathrm{H}$

$\mathrm{Q}$ air total $=\mathrm{Q}$ air sensible $+\mathrm{Q}$ air laten

Menghitung Q etanol

$\mathrm{Q}$ etanol $($ sensible $)=\mathrm{m} \cdot \mathrm{c} \cdot \Delta \mathrm{T}$

$\mathrm{Q}$ etanol (laten) $\quad=\mathrm{m} . \Delta \mathrm{H}$

Q etanol total = $\mathrm{Q}$ etanol sensible $+\mathrm{Q}$ etanol laten

Menghitung Q total

$\mathrm{Q}$ total $=\mathrm{Q}$ air total $+\mathrm{Q}$ etanol total 
Pada perhitungan perencanaan tangki pemanas dapat dilihat pada tabel 1. dibawah ini

Tabel 1. Hasil perhitungan perencanaan tangki pemanas

\begin{tabular}{ll}
\hline Perhitungan & Hasil \\
\hline Volume bahan baku & $200 \mathrm{~mm}$ \\
Volume total & 68,8 liter \\
Volume penguapan & 37,8 liter \\
Kebutuhan uap & $50 \mathrm{~kg} / \mathrm{jam}$ \\
Waktu penyulingan & $30 \mathrm{menit}$ \\
Kebutuhan kalor & $514102 \mathrm{~kJ} / \mathrm{jam}$ \\
Kebutuhan bahan bakar & $11 \quad \mathrm{~g} / \mathrm{jam}$ \\
\hline
\end{tabular}

\subsection{Simulasi Design}

Pengujian pada tangki pemanas untuk destilator bioetanol ini dilakukan dengan analisa beban statis pada tangki ini mengguankan Software Engineering Design. Diasumsikan tekanan dalam tangki 5 bar sesuai dengan safety valve. Pada hasil simulasi design ini, maka diperoleh data pada gambar 3 sebagai berikut:
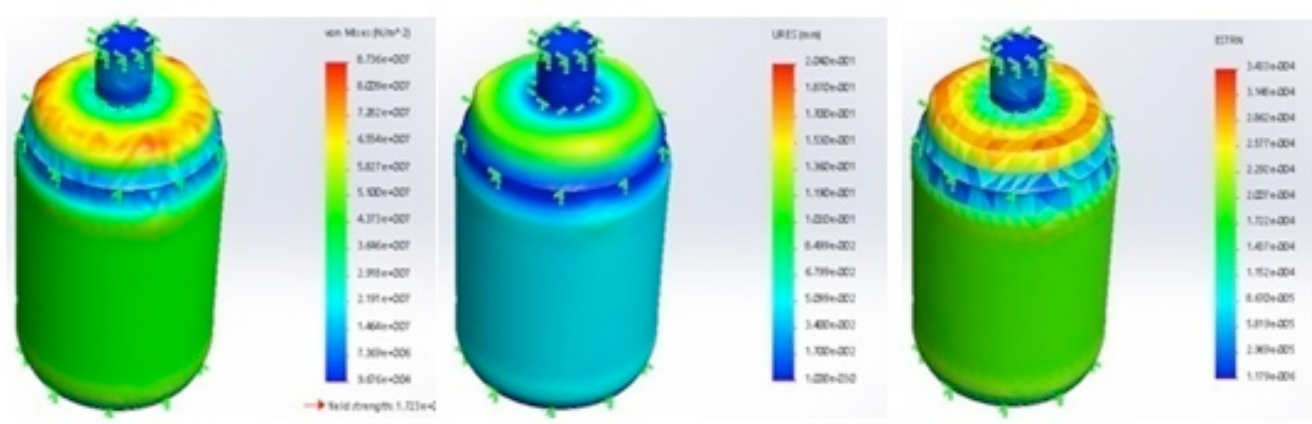

Gambar 3. Hasil simulasi

Pada hasil simulasi design dapat dilihat pada tabel 2 berikut :

Tabel 2. Mechanical properties

\begin{tabular}{ll}
\hline Properties & Value \\
\hline Yield Strength & $2 \times 10^{8} \mathrm{~N} / \mathrm{m}^{2}$ \\
Tensile Strength & $5 \times 10^{8} \mathrm{~N} / \mathrm{m}^{2}$ \\
Elastic Modulus & $2 \times 10^{11} \mathrm{~N} / \mathrm{m}^{2}$ \\
Poisson Ratio & 0,28 \\
Mass Density & $7800 \mathrm{~kg} / \mathrm{m}^{3}$ \\
Shear Modulus & $7 \times 10^{10} \mathrm{~N} / \mathrm{m}^{2}$ \\
Thermal Expansion Coefficient & $1 \times 10^{-5} / \mathrm{K}$ \\
\hline
\end{tabular}

\subsection{Perhitungan Bejana Tekan}

Proses perhitungan bejana tekan pada tangki pemanas destilator sistem continue dibutuhkan proses pehitungan bejana tekan untuk mempermudah proses pembuatan atau perancangan. Untuk tegangan tarik ijin pada tangki pemanas adalah $102,5 \mathrm{~N} / \mathrm{mm}^{2}$ [5] 
Untuk menghitung mengenai kekuatan dinding ketel terhadap kemungkinan belah dan kemungkinan putus dapat dihitung sebagai berikut

Tebal tangki terhadap kemungkinan belah (tb)

$t_{b}=\frac{D \cdot p}{2 \cdot \sigma_{t}(1+D / L)}$

Tebal tangki terhadap kemugkinan putus (tp)

$t_{p}=\frac{p \cdot D}{4 \cdot \sigma_{t}}$

Hasil perhitungan tebal tangki terhadap kemungkinan putus dan kemungkinan belah dapat dilihat pada tabel 3 dibawah ini:

Tabel 3. Hasil perhitungan tebal tangki

\begin{tabular}{ll}
\hline Perhitungan & Hasil \\
\hline Tebal tangki terhadap kemungkinan belah & $0,46 \mathrm{~mm}$ \\
(tb) & \\
$\begin{array}{l}\text { Tebal tangki terhadap kemungkinan putus } \\
\text { (tp) }\end{array}$ & $0,45 \mathrm{~mm}$ \\
\hline
\end{tabular}

Perhitungan tebal dinding terhadap temperatur kerja tangki pemanas dengan tekanan dalam tangki 5 bar sesuai safety factor pada tangki tersebut.

$$
S=\frac{p \cdot D}{200 \cdot \frac{K}{s} \cdot U}+1
$$

Gaya yang membelah pada bejana $(\mathrm{P})$

$$
P=L \times D \times p
$$

Gaya sebesar $(\mathrm{P})$ ditahan oleh dinding bejana, dengan luasan irisan $\left(\mathrm{A}_{1}\right)$ adalah :

$A_{1}=\{2 \times x L \times t+2 \times t(D+2 t)\}$

Dengan terjadinya tegangan didalam dinding bejana tekan sebesar $\delta$ t, maka dapat ditentukan sebagai berikut :

$A_{1} \cdot \sigma t=L \cdot D \cdot p$

Analisa gaya yang mwngakibatkan plat bejana putus

$P=\frac{\pi}{4} D^{2} \cdot p$

Gaya sebesar $(\mathrm{P})$ akan ditahan oleh dinding bejana tekan, dengan luas irisan $\left(\mathrm{A}_{2}\right)$ adalah :

$A_{2}=\frac{\pi}{4}\left(4 \cdot D \cdot t+4 t^{2}\right)$ 
Dengan terjadinya tegangan didalam dinding bejana tekan sebesar $\delta$, maka dapat ditentukan sebagai berikut :

$A_{2} \cdot \sigma t=P$

$\sigma_{t i j i n} \geq \sigma_{t}$ artinya tegangan yang diijinkan $\left(\sigma_{t}\right.$ ijin $)$ lebih besar dibandingkan dengan tegangan yang terjadi didalam bejana $\left(\sigma_{t}\right)$, maka bejana tekan dinyatakan aman. Hasil perhitungan gaya pada bejana tekan dapat dilihat pada tabel 4 berikut.

Tabel 4. Hasil perhitungan gaya pada bejana

\begin{tabular}{ll}
\hline Perhitungan & Hasil \\
\hline $\begin{array}{l}\text { Tebal tangki terhadap temperature } \\
\text { kerja }\end{array}$ & $2 \mathrm{~mm}$ \\
Gaya yang membelah dinding & $95,2 \mathrm{~N} / \mathrm{mm}^{2}$ \\
Gaya yang meutuskan dinding & $45 \mathrm{~N} / \mathrm{mm}^{2}$ \\
\hline
\end{tabular}

Analisa tegangan memanjang atau searah bejana tekan (longitudinal) yang terjadi pada bejana tekan, karena ada gaya yang ada dalam bejana tekan akan yang arahnya searah dengan posisi bejana tekan (longitudinal) maka menimbulkan suatu tegangan.

$S_{1 \sigma}=\frac{p \cdot D}{4 t}$

$\sigma_{\mathrm{tijin}} \geq \mathrm{S}_{1 \sigma}$ artinya tegangan yang diijinkan $\left(\sigma_{\mathrm{t}} \mathrm{ijin}\right)$ harus lebih besar dibandingkan dengan tegangan longitudinal yang terjadi didalam bejana $\left(\mathrm{S}_{1 \sigma}\right)$, maka bejana dinyatakan aman.

Analisa tegangan melingkar atau searah diameter bejana (cirumferential) yang terjadi pada bejana bertekanan arena adanya gaya yang ada dalam bejana tekan yang arahnnya melingkar dengan diameter bejana tekan (circumferential), maka akan menimbulkan suatu tegangan.

$S_{2 \sigma}=\frac{p \cdot D}{2 t}$

$\sigma_{\text {tijin }} \geq \mathrm{S}_{2 \sigma}$ artinya tegangan yang diijinkan $\left(\sigma_{\mathrm{t} i j i n}\right)$ lebih besar dibandingkan dengan tegangan circumferential yang terjadi didalam bejana $\left(\mathrm{S}_{2 \sigma}\right)$, maka bejana dinyatakan aman.

Analisa pertambahan panjang (expantion) yang terjadi pada bejana tekan dimana sebelum kita mencari pertambahan panjang, terlebih dahulu mengetahui angka atau konstanta yang diperlukan.

$\Delta \mathrm{L}=\frac{\Delta \mathrm{t} \cdot \mathrm{L} \cdot \mathrm{k}}{100}$

Pada hasil perhitungan tegangan bejana tekan dapat dilihat pada tabel 5 berikut :

Tabel 5. Hasil perhitungan tegangan pada bejana tekan

\begin{tabular}{lc}
\hline Perhitungan & Hasil \\
\hline Tegangan longitudinal & $50 \mathrm{~N} / \mathrm{mm}^{2}$ \\
Tegangan cirumferential & $100 \mathrm{~N} / \mathrm{mm}^{2}$ \\
Pertambahan panjang & $0,45 \mathrm{~mm}$ \\
\hline
\end{tabular}




\subsection{Proses Pengujian}

Pada pengujian ini dilakukan pengujian software simulasi, pengujian tangki pemanas, pengujian destilator bertujuan untuk proses perancangan pada tangki pemanas dan pengujian lapangan untuk mengetahui sistem kerja tangki pemanas pada destilator bioetanol sehingga akan didapatkan kapasitas hasil yang sesuai dengan perencanaan yang diharapkan.

Pengujian pada tangki pemanas untuk destilator bioetanol ini dilakukan dengan analisa beban statis pada tangki ini menggunakan Software Engineering Design. Tujuan dari analisa statis ini adalah untuk mengetahui titik terlemah dari tegangan Von Mises Stress, Displacement, Strain. Pada hasil simulasi dapat dilihat pada tabel 6 berikut ini :

Tabel 6. Hasil simulasi

\begin{tabular}{lll}
\hline Name & Minimum & Maximum \\
\hline Mass & $14,663 \mathrm{~kg}$ & - \\
Volume & $0,00187987 \mathrm{~m}^{3}$ & - \\
Von Mises Stress & $88510 \mathrm{~N} / \mathrm{m}^{2}$ & $9 \times 10^{7} \mathrm{~N} / \mathrm{m}^{2}$ \\
Displacement & $0 \mathrm{~mm}$ & $0,208548 \mathrm{~mm}$ \\
Strain & $9 \times 10^{-7}$ & 0,000340344 \\
\hline
\end{tabular}

Berdasarkan tabel pengujian software dengan tekanan 5 bar didapatkan hasil perbandingan Von Mises Stress $9,9 \times 10 \mathrm{~N} / \mathrm{m}^{7} \mathrm{~N} / \mathrm{m}^{2}$ Sehingga tangki dinyatakan aman karena Von Mises Stress lebih kecil dibandingkan dengan material bahan Yield Strenght $2 \times 10^{8} \mathrm{~N} / \mathrm{m}^{2}$

Perhitungan galat presentase pada bejana tekan meliputi von mises stress dan dicplacement adalah sebagai berikut :

$\%$ eror $=\frac{\text { perhitungan teoritis }- \text { simulasi software }}{\text { simulasi software }} .100$

Pada hasil perhitungan galat dapat dilihat pada tabel 7 berikut

Tabel 7. Hasil perhitungan galat

\begin{tabular}{lc}
\hline Perhitungan & Hasil \\
\hline Von Misess Stress & $1,0 \%$ \\
Displacement & $1,9 \%$ \\
\hline
\end{tabular}

Pengujian tangki pemanas bertujuan untuk menentukan aman tidaknya sistem kerja tangki pada temperature tertentu. Pada pengujian tangki pemanas melalui beberapa pengujian diantaranya adalah kebocoran pada tangki dengan cara menganalisa sistem kerja tangki. Hasil perhitungan pengujian tangki pemanas dapat dihilat pada tabel 8 berikut :

Tabel 8. Hasil pengujian tangki pemanas

\begin{tabular}{llllll}
\hline No & $\begin{array}{l}\text { Bahan Baku } \\
(\boldsymbol{l})\end{array}$ & $\begin{array}{l}\text { Temperatur } \\
\text { Tangki } \\
\left({ }^{\circ} \mathbf{C}\right)\end{array}$ & $\begin{array}{l}\text { Waktu } \\
(\text { menit) }\end{array}$ & Kebocoran & Ketahanan \\
\hline 1 & 50 & 50 & 45 & Tidak & Aman \\
2 & 50 & 75 & 60 & Tidak & Aman \\
3 & 50 & 100 & 75 & Tidak & Aman \\
\hline
\end{tabular}


Pengujian tangki pemanas ini dibutuhkan bahan baku fermentasi 50 liter dan berdasarkan pengujian dengan variasi temperatur kerja tangki $\left(50^{\circ} \mathrm{C}, 75^{\circ} \mathrm{C}, 100^{\circ} \mathrm{C}\right)$ hasil yang didapatkan tangki masih aman untuk beroprasi

Pengujian destilator bertujuan untuk mengetahui hasil etanol terhadap lama fermentasi menggunakan tetes tebu sebagai bahan ujinya. Pada pengujian ini hasil yang diperoleh adalah kapasitas hasil dan tingkat kemurnian etanol. Hasil pengujian tangki pemanas dapat dilihat pada tabel 9 dibawah ini.

Tabel Hasil 9. Pengujian tangki pemanas

\begin{tabular}{lllllll}
\hline No & $\begin{array}{l}\text { Bahan } \\
\text { Baku } \\
(\boldsymbol{l})\end{array}$ & $\begin{array}{l}\text { Lama } \\
\text { Fermentasi } \\
(\text { hari) }\end{array}$ & $\begin{array}{l}\text { Temperatur } \\
\text { Refluks } \\
\left({ }^{\circ} \mathbf{C}\right)\end{array}$ & $\begin{array}{l}\text { Waktu } \\
\text { Destilasi } \\
(\text { jam })\end{array}$ & $\begin{array}{l}\text { Hasil } \\
\text { Etanol }(\boldsymbol{l})\end{array}$ & $\begin{array}{l}\text { Kadar } \\
\text { Etanol } \\
(\%)\end{array}$ \\
\hline 1 & 50 & 7 & 78 & 1 & 2,27 & 91 \\
\hline
\end{tabular}

Berdasarkan hasil pengujian mesin destilator bioetanol dengan lama fermentasi 7 hari di dapatkan hasil etanol 2,27 liter dengan kadar etanol $91 \%$.

\section{KESIMPULAN}

Dari rancang bangun tangki pemanas destilator bioetanol dapat disimpulkan sebagai berikut :

1. Design tangki pemanas menggunakan plat Stainless Steel 304 dengan tinggi $675 \mathrm{~mm}$, diameter $400 \mathrm{~mm}$, dan tebal $2 \mathrm{~mm}$ dengan menggunakan sistem continue otomatis.

2. Simulasi menggunakan Software Enginering Design, hasil yang diperoleh dengan nilai maksimal von mise $9 \times 10^{7} \mathrm{~N} / \mathrm{mm}^{2}$, displacemen $0,02 \mathrm{~mm}$, strain 0,00034 , pada simulasi ini didapatkan kesimpulan bahwa nilai maksimal dari von mises lebih rendah dari yield strength material bahan maka tangki pemanas dinyatakan aman.

3. Pada proses pengujian mesin dengan bahan baku tetes tebu didapatkan hasil etanol 2,35 liter/jam dengan tingkat kemurnian etanol 91\%.

\section{DAFTAR PUSTAKA}

[1] Hambali, Erliza, and S. Mujdalipah, Teknologi Bioenergi. Jakarta, 2007.

[2] R. Winarso, B. S. Nugraha, and Taufiq Santoso, "Pengembangan Alat Destilator Bioetanol Model Refluk," J. SIMETRIS, vol. 5, no. 2, p. 104, 2014.

[3] R. Winarso, B. S. Nugraha, A. Muttaqin, and N. Rofiudin, "Pemgembangan Alat Destilator Bioetanol Sebagai Bahan Bakar Alternatif," vol. Prossiding, pp. 7-12, 2014.

[4] M. Ischsan, B. S. Nugraha, and R. Winarso, "Analisa Pengaruh Lama Fermentasi Terhadap Kadar Bioetanol Pada Mesin Destilator Model Reflux,” J. SIMETRIS, vol. 6, no. 2, p. 318, 2015.

[5] Djokosetyardjo, KETEL UAP. Jakarta: Paradndya Paramita, 2003. 